\title{
A Shape Memory Alloy Application for Compact Unmanned Aerial Vehicles
}

\author{
Salvatore Ameduri ${ }^{1, *, \dagger}$, Antonio Concilio ${ }^{1, \dagger}$, Nunzia Favaloro ${ }^{2, \dagger}$ and Lorenzo Pellone ${ }^{3, \dagger}$ \\ 1 Adaptive Structures Department, Centro Italiano Ricerche Aerospaziali, Via Maiorise, Capua 81043, Italy; \\ a.concilio@cira.it \\ 2 Space Exploration and Propulsion Facilities, Centro Italiano Ricerche Aerospaziali, Via Maiorise, \\ Capua 81043, Italy; n.favaloro@cira.it \\ 3 Aeronautics Systems Engineering Department, Centro Italiano Ricerche Aerospaziali, Via Maiorise, \\ Capua 81043, Italy; 1.pellone@cira.it \\ * Correspondence: s.ameduri@cira.it; Tel.: +39-823-623-556 \\ + These authors contributed equally to this work.
}

Academic Editor: Javaan Chahl

Received: 2 March 2016; Accepted: 20 May 2016; Published: 31 May 2016

\begin{abstract}
Shape memory alloys materials, SMA, offer several advantages that designers can rely on such as the possibility of transmitting large forces and deformations, compactness, and the intrinsic capability to absorb loads. Their use as monolithic actuators, moreover, can lead to potential simplifications of the system, through a reduction of number of parts and the removal of many free play gaps among mechanics. For these reasons, technological aerospace research is focusing on this kind of technology more and more, even though fatigue life, performance degradation, and other issues are still open. In the work at hand, landing gear for unmanned aerial vehicles, UAV, is presented, integrated with shape memory alloys springs as actuation devices. A conceptual prototype has been realized to verify the system ability in satisfying specs, in terms of deployment and retraction capability. Starting from the proposed device working principle and the main design parameters identification, the design phase is faced, setting those parameters to meet weight, deployment angle, energy consumption, and available room requirements. Then, system modeling and performance prediction is performed and finally a correlation between numerical and experimental results is presented.
\end{abstract}

Keywords: shape memory alloys; landing gear; deployable systems

\section{Introduction}

Parachutes are used in a wide variety of applications, including sport activities, payload recovery, military applications, and flood relief efforts. Paraglider is quite popular within the sports community. Unlike the conventional round canopy parachutes, they have a large lift-to-drag ratio and are easily maneuverable. Recently, defense organizations, all over the world, have shown a growing interest in deploying paragliders for many applications.

Worthy of note are the works on the use of paragliders and UAVs performed by: Nagy and Rohacs [1], related with the development of an unmanned system for testing different paragliders; Eschmann et al. [2], aircraft platform management and autonomous software development; Jacob and Smith [3], development, testing and integration of inflatable wings for small UAVs; [4], an assessment of the viability of using a powered parafoil as an unmanned air vehicle for employment of Future Combat System intelligence, surveillance, and reconnaissance unattended ground sensors (UGS); and [5], lessons learned of the Parafoil Technology Demonstration (PTD) Project.

Shape Memory Alloys, SMA, due to their ability in transmitting large forces and deformations and to their intrinsic compactness, may play a critical role as actuation and load absorbing elements within 
deployable architectures. Among the different applications in this field one recalls: the lightweight flexible solar array, actuated by SMA flexible hinges, proposed by Carpenter and Lyons [4]; the deployable auxetic SMA cellular antenna demonstrator developed by Jacobs et al. [6]; the deployable tabs and flaps break up vortices developed by Boeing [7]; the deployable mirrors developed by Pollard and Jenkins [8]; the use of SMA materials to actuate antenna deployable architectures, proposed by Sofla et al. [9]; the SMA based deployable tube, patented by Unsworth and Waram [10]; the SMA based landing gear for airships, developed by Dayananda et al. [11]. More specifically, for the UAV and the aerial vehicles one recalls the investigations on the use of the SMA materials to reduce or eliminate the servo actuators for morphing $[12,13]$ and the application of SMA active elements to deform aircraft aerodynamic surfaces [14].

CIRA, the Italian Aerospace Research Centre, in the framework of the "Small Unmanned Aerial System" (SUAS) Military National Research Program (PNRM) with the support of Aerosekur, has carried out a feasibility study concerning small Unmanned Aerial Systems (UAS) exhibiting good levels of transportability and configurability speed, equipped with a parafoil wing, for patrolling, intelligence, surveillance, reconnaissance, and telecom networking.

In Figure 1, the main components of the cited UAS are shown, namely the sail, the fuselage and the interior systems. The main system features are reported in Table 1.

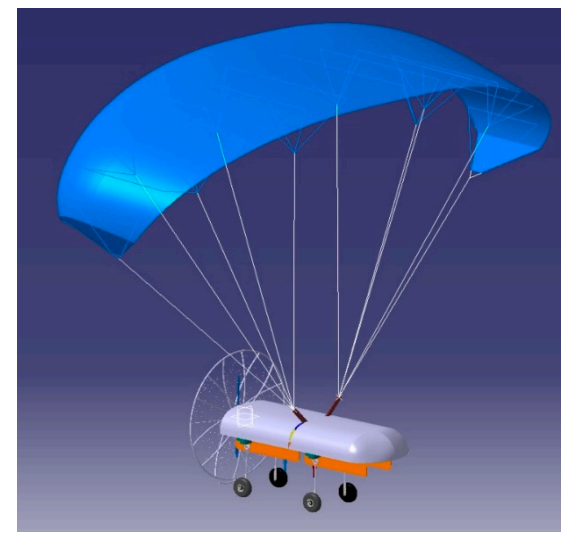

(a)

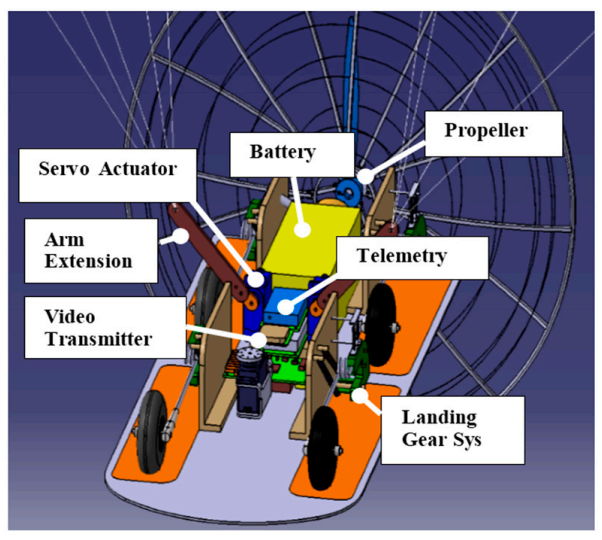

(b)

Figure 1. Unmanned Aerial Systems (UAS) main components: sail, fuselage (a); interior systems (b).

Table 1. UAS main features.

\begin{tabular}{cccc}
\hline Sail Span $(\mathbf{m})$ & Sail Area $\left(\mathbf{m}^{\mathbf{2}}\right)$ & Weight $(\mathbf{k g})$ & Energy $(\mathbf{W h})$ \\
\hline 1.6 & 2.4 & 5.0 & 38.5 \\
\hline
\end{tabular}

The system is conceived to perform missions at low altitude ( $300 \mathrm{~m}$ above the sea level) and short endurance $(1 \mathrm{~h})$. Different payloads and sensors can be installed, depending on the selected mission (fixed and mobile targets identification, border patrol, traffic control and many others, involving also civil applications). The main subsystems are the fuselage and the parafoil (or "sail"), connected to the main body by wires. The fuselage hosts the flight control unit, the power supply, the engine, the payload, and the landing gear. All the components are designed to allow compact packaging and rapid deployment on the ground, to keep the system mass, complexity, and cost low.

A peculiar aspect of this system is the ability to land on very different runways, according to the different missions. Therefore, the landing gear must guarantee the right flexibility and damping to protect the payload. Following this necessity, CIRA has developed landing gear, driven by a shape memory alloys (SMA) system. SMA active elements regulate the deployment of the landing gear on take-off and landing, whereas SMA bias springs assure the retraction during cruise [15]. 
In the paper at hand, the working principle of a SMA-based landing gear is described, highlighting the function of its main components and the way they interact each other. For this purpose, dedicated structural schemes are conceived, and used as reference for designing the retracted and the deployed configurations. Starting from system and mission requirements (available room within the fuselage, weight limits, available energy, activation time, and so on), the design phase is carried out: the main system parameters are first identified, like the springs characteristic, their layout and their connections with the landing gear arms; then a suitable numerical model is developed, able to fix its features and predict its performance, and finally a dedicated conceptual mock-up is manufactured, reproducing the arm rotating shaft, the pivot connection element with the SMA springs, and the springs themselves.

The system functionality has been evaluated in terms of ability in deploying and retracting the landing gear and the demonstrator has been tested for several cycles, giving evidence of the working process repeatability and reliability. The evolution of kinematic and thermodynamic parameters (arm rotation and SMA temperature) is finally presented, giving evidence of the strong relation between them during system activation and de-activation.

\section{Working Principle and Design Requirements}

The landing gear system proposed in this work is conceived to give rise to the complete deployment of its arms on take-off and landing and to guarantee their full retraction during cruise and other flight phases. Figure 2 shows an open view of the fuselage in these two moments. The landing gear is made of four arms intrinsically able to absorb the impact loads without any additional damping mechanism. A $90^{\circ}$ rotation of the arms around the pivots shall be produced by the SMA actuation system. For lateral stability issues, the rotation plane of each couple of lateral arms has a $2.5^{\circ}$ slope with respect to the vertical symmetry plane. Each arm is constituted by an aluminum alloy stick with a spring in order to absorb the impact energy.

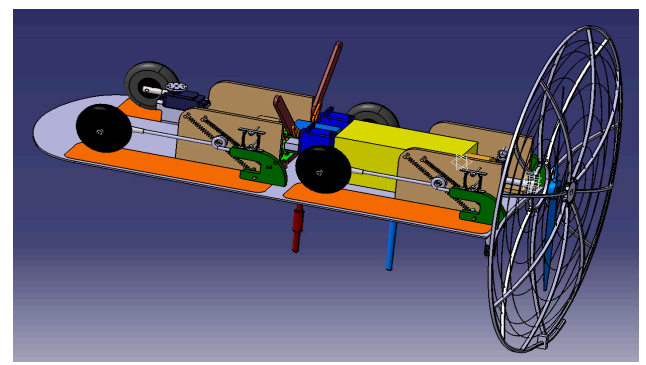

(a)

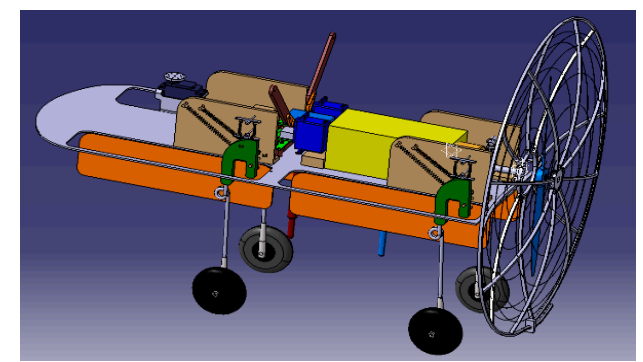

(b)

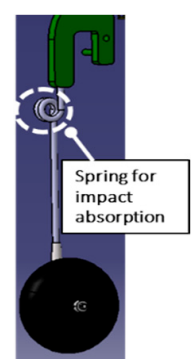

(c)

Figure 2. Fuselage open view: retracted (a) deployed arms (b); arm detail (c).

The landing gear herein proposed consists of two main subsystems, both based on SMA technology: the deployment-retraction and the blocking subsystems. The former is made in turn of two bias SMA springs whose super elastic behavior falls within the UAS temperature working range. They are pre-stressed around the arm pivot and reach equilibrium once the landing gear is retracted, Figure 3a. The top spring heating shall cause the alloy changes its phase, with an increment of its rigidity; as a consequence, the equilibrium point shifts and a rotation $\vartheta$ is induced towards the deployment direction, Figure 3b.

Points A and C, spaced by a distance $\mathrm{d}$, represent the connections of the springs to the shaft $\mathrm{O}$ and are symmetric with respect to the shaft itself. The springs are parallel and connected to the fuselage body at the points $B$ and $D$. The dimensions $b$ and $h$ define the positions of these points with respect to the shaft $\mathrm{O}$ in the adopted reference plane. The center of gravity (c.g.) of the arm-wheel system is at a distance $b_{\mathrm{w}}$ from the pivot. A mass, $m_{\mathrm{b}}$, on the opposite side of the pivot, balances the weight of the arm-wheel system. It is possible to increase the internal stress of the antagonistic spring to achieve the same balance, but this would have led to an additional pre-strain, exceeding material stress limits. 


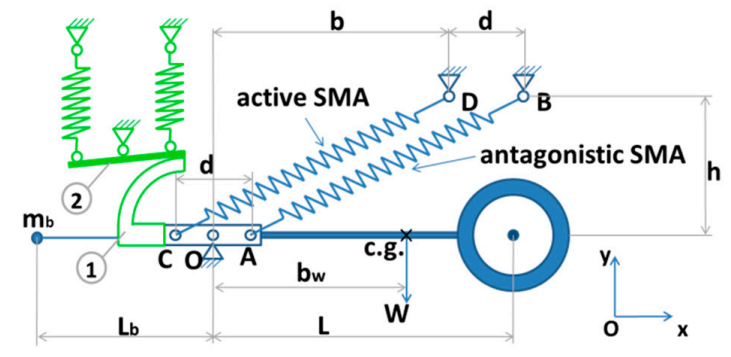

(a)

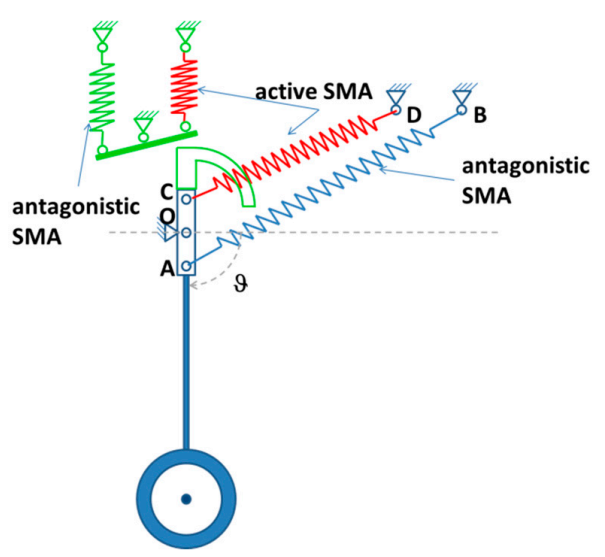

(b)

Figure 3. Reference structural schemes: retracted (a) and deployed configurations (b). Points A-D represent the hinges of the SMA springs used for deploying the arm of the landing gear; $\mathrm{O}$ is the pivot of the arm; $W$ is the weight of the arm applied on its center of gravity, c.g.; $L$ and $L_{\mathrm{b}}$ represent the distances of the wheel axis and of the additional mass $m_{\mathrm{b}}$ from the pivot $\mathrm{O}$; finally the green assembly represents the blocking system.

The blocking subsystem (green sketch, Figure 3) is introduced to guarantee increase stability to the retracted and the deployed configurations without significant oscillations. It is in turn made of two parts, one rigidly connected to the hub AC and the other one actuated by two further SMA antagonistic springs. These latter are also pre-stressed, so that the brake component $(2$, circled in the figure above) is pushed against the rotational component (1, circled in the figure above) to clutch it. The activation of the spring on the right, Figure $3 b$, synchronous with the activation of the top spring of the deployment subsystem, unlocks the hub and allows opening the landing gear.

Once the working principle is described, in order to design the landing gear system, the following requirements are set:

- Deployment rotation and response time: the SMA system must guarantee a rotation equal to or larger than $90^{\circ}$ within $10 \mathrm{~s}$. Due to SUAS mission requirements, above all altitude and air speed, a 10-s time is sufficient to guarantee the right landing procedure. More in detail, the reference UAV has a $350 \mathrm{~m}$ operative altitude and a $1 \mathrm{~m} / \mathrm{s}$ descent rate. The idea is to open the landing gear at $100 \mathrm{~m}$ altitude, and after $10 \mathrm{~s}$, to continue the descent for about $90 \mathrm{~s}$ with a fully deployed landing gear.

- Arm retraction: the arm must be completely stowed within the fuselage within $150 \mathrm{~s}$ from take-off.

- Weight: the total weight of the landing gear actuator system, including the hub and the clutches, must be less than $30 \mathrm{~g}$. This is one of the most important strengths of the system. In fact, this kind of device weighs about $50 \mathrm{~g}$ for models up to $5 \mathrm{~kg}$. More in detail at the present project stage, the low smart actuator weight allows the possibility of onboarding a pan \& tilt camera, able to monitor woods/forests, in support of Civil Protection and State Park Rangers patrols during fire-detection missions, or monitoring the zone of disaster in support to emergency teams, and so on.

- $\quad$ Power-energy supply: power absorption shall be lower than $4 \mathrm{~W}$. Assuming a $10 \mathrm{~s}$ deployment time, this value corresponds to $0.01 \mathrm{Wh}$.

- Room: the available volume is $7 \mathrm{~cm} \times 10 \mathrm{~cm} \times 5 \mathrm{~cm}$.

\section{Sizing the Shape Memory Alloys (SMA) Deployment Subsystem}

The design process referred to the structural schemes, illustrated in Figure 3. Parameter $d$ (distance between points $\mathrm{A}$ and $\mathrm{C}$ ) was fixed after a compromise between two opposite necessities: maximizing 
the transmitted rotation (conversely proportional to $d$ ) and avoiding interferences between the springs during the activation phase (directly proportional to $d$ ).

Distances $h$ and $b$ are instead set after considerations about the necessity of avoiding overlaps and fitting the available room. Assuming two springs whose features are reported in Table 2, these geometric values resulted: $d=2 \mathrm{~cm}, h=6 \mathrm{~cm}$ and $b=7 \mathrm{~cm}$. More in detail, the parameter $d$ has been assumed equal to the distance between the spring connections to the gear arm (points $\mathrm{A}$ and $\mathrm{C}$ of Figure 3a); this assures the parallelism of the two spring in fully retracted condition. Note that, for the retracted configuration, the two springs are in the closest relative position. When activated, they move away each other (as shown in Figure $3 b$ ) avoiding any interference. The distance of the connections $\mathrm{A}$ and $\mathrm{C}$ has been chosen to guarantee a full conversion (more than $90^{\circ}$ of rotation) of the spring linear displacement into rotation around the arm pivot $\mathrm{O}$. The parameter $h$, that is the vertical distance between point $\mathrm{A}$ and $\mathrm{C}$ and between $\mathrm{B}$ and $\mathrm{D}$, was chosen as the maximum allowable for the internal space (fuselage height), thus preventing as much as possible any mechanical conflict between the two springs; finally the parameter $b$ was chosen to assure, in combination with already fixed $d$ and $h$ the necessary stretched length of the two springs.

Table 2. Characteristic of the shape memory alloys (SMA) springs.

\begin{tabular}{|c|c|c|c|c|c|c|c|c|}
\hline $\begin{array}{l}\text { Spring } \\
\text { Diameter } \\
(\mathrm{mm})\end{array}$ & $\begin{array}{c}\text { Wire } \\
\text { Diameter } \\
(\mathrm{mm})\end{array}$ & Windings & $\begin{array}{l}\text { Length } \\
\text { without } \\
\text { Loads } \\
\text { (mm) }\end{array}$ & $\begin{array}{l}\text { Material (See } \\
\text { Load and } \\
\text { Unload } \\
\text { Cycles in) }\end{array}$ & $\begin{array}{l}\text { Austenite } \\
\text { Young } \\
\text { Modulus } \\
\text { (GPa) }\end{array}$ & $\begin{array}{l}\text { Martensite } \\
\text { Young } \\
\text { Modulus } \\
\text { (GPa) }\end{array}$ & $\begin{array}{l}\text { Transformation } \\
\text { Temperatures, As, } \\
\text { Af, Ms, Mf, Rs, } \\
\text { Rf }\left({ }^{\circ} \text { C) [16-19] }\right.\end{array}$ & $\begin{array}{l}\text { Density } \\
\left(\mathrm{kg} / \mathrm{m}^{3}\right)\end{array}$ \\
\hline 4.5 & 0.55 & 38 & 27.8 & NiTiNol & 103.3 & 57.7 & $\begin{array}{c}65.9 ; 78.4 ; \\
36.4 ;-3.8 ; \\
73.7 ; 49.8\end{array}$ & 6450 \\
\hline
\end{tabular}

The material chosen for the springs, NiTiNol (Ni 49.8\%), was experimentally characterized; the Austenite and Martensite Young moduli were determined through tensile tests (also aimed at stabilizing the material) and DSC measurements. Achieved results are illustrated in the graphs of Figure 4. After seven cycles, the curve convergence (stabilization) was observed.

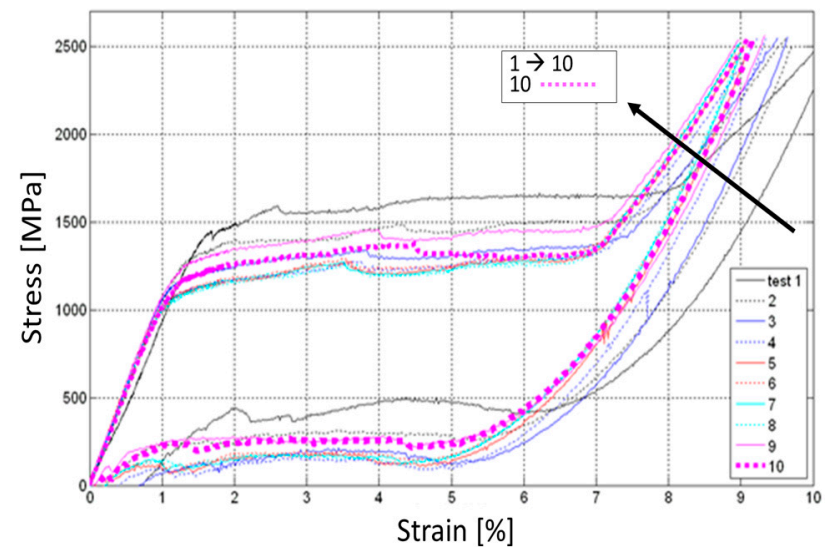

(a)

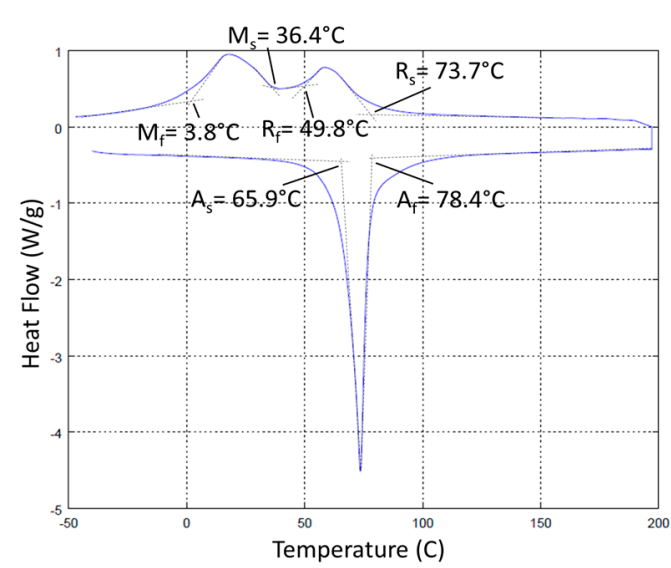

(b)

Figure 4. Experimental characterization of the spring material: tensile cycles (a); DSC measurements (b). In the figure, 10 cycles are reported. They show an oscillating behavior, convergent towards the dotted line.

The analyses hereafter illustrated prove the correctness of that choice.

At first, the springs were experimentally characterized for having an estimate of the elastic reaction; in Figure 5, the force, displacement curves at room temperature $\left(20^{\circ} \mathrm{C}\right)$ and for the complete activation (full austenite) condition, are plotted. The upper curve refers to the pure austenite condition; 
this curve is obtained by keeping a temperature higher than the minimum one necessary to have full austenite at a certain stress level; the lower curve, on the other hand, refers to a partial martensite concentration (see Ms and Mf values reported in Table 2); as the load arises, since the temperature is kept constant, the transformation into martensite progresses. In practice, the higher the axial force, the higher the torque moment acting onto the wire cross section; this leads to larger tangential displacements of the external zones of the wires, where austenite transformation into martensite starts.

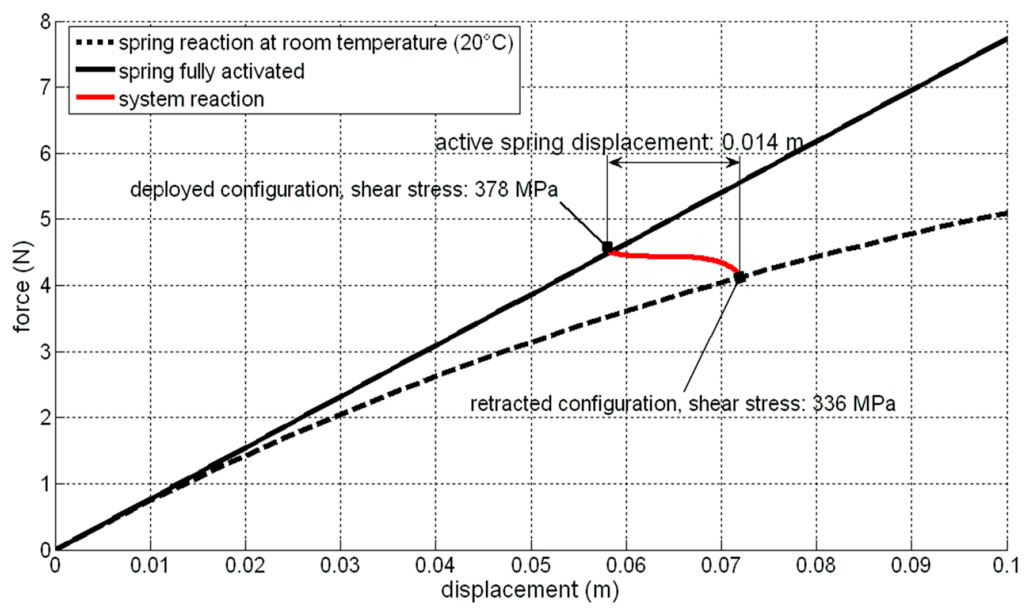

Figure 5. Force-displacement curves for the springs of the deployment subsystem: room temperature (black dashed line), full austenite (black solid line); landing gear system reaction (red line).

These springs are in martensite phase at room temperature, without applied load (see transformation temperatures reported in Table 2).

The approach illustrated in Figure 6 is instead used to verify that the selected geometric parameters value effectively meet the original specifications.

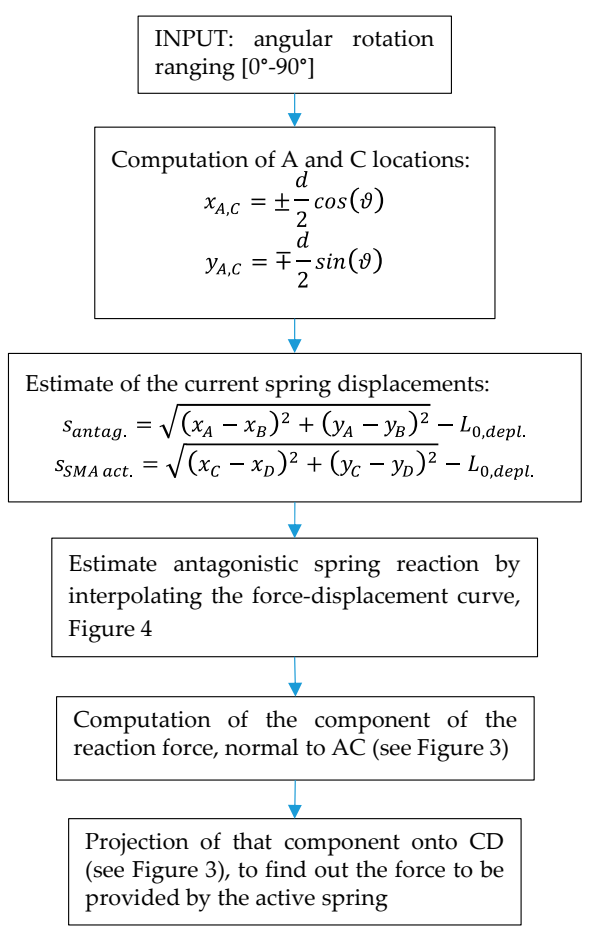

Figure 6. Flowchart used for the estimate of the equilibrium configuration of the system. 
Each angular rotation, $\vartheta$, is, in fact, related to the spring length (i.e., the distances of $A$ and $C$ from $\mathrm{B}$ and $\mathrm{D}$, respectively). For the bias spring $\mathrm{AB}$ it is thus possible to compute the elastic reaction at the point $\mathrm{A}$. The force component normal to the segment $\mathrm{AC}$ is then projected onto the $\mathrm{CD}$ direction (active spring orientation) to evaluate the balance force the active spring must provide.

In Figure 7, the rotation around the pivot, the displacement of the bias, and the active springs are plotted vs. the balancing force. This latter curve plays a critical role for the design, representing the system rigidity as perceived by the SMA active spring, and can be used to graphically estimate the non-activated (arm retracted) and activated (arm deployed) equilibrium conditions.

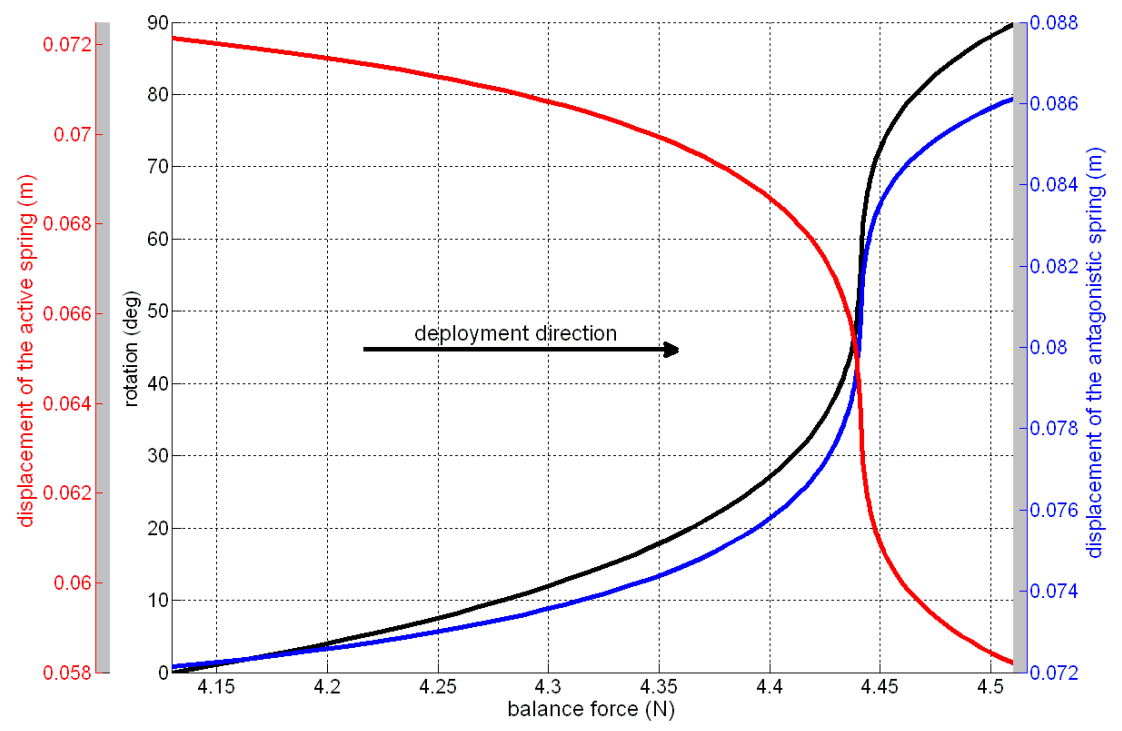

Figure 7. Balancing force vs. rotation (black) and displacement of the antagonistic (blue) and the active (red) springs.

The nonlinear behavior of the system is highlighted by the remarkable slope variation of the force-rotation and force-displacement curves, mainly due to the springs' nonlinear force-displacement law, Figure 6, and to the variation of the distances of the force application points from the pivot.

The system action, as perceived by the SMA active spring, intersects the non-activated (black dashed line) and the fully activated (black continuous line) force-displacement curves in two different points, corresponding to the retracted and fully deployed configurations, Figure 7 . A $16 \mathrm{~mm}$ displacement is required to the active spring, to achieve the desired deployment. The shear stress level, $\tau$, within the antagonistic spring is evaluated by [20]:

$$
\tau=8 \frac{F D_{s}}{\pi d_{w}^{3}}
$$

being $F$ the force acting on the spring, $D_{s}$ and $d_{w}$ the spring and the wire diameters. A maximum value of $378 \mathrm{MPa}$ is found for the fully deployed configuration, well under the allowable limit of $450 \mathrm{MPa}$. Equation (1) comes from the torque equilibrium of the wire of the spring. This torque moment is the result of the axial force applied to the spring, which is transmitted at each cross section of the wire as rotation and thus as shear action. The relation between the applied axial load $F$ and the elongation produced is not linear during the load cycle; however the present study aims at comparing two well-established, extreme configurations: no activated (pure martensite) and fully activated (pure austenite and at such a temperature to assure the only austenite for the occurring stress level). 
The balancing mass, $m_{\mathrm{b}}$, was finally estimated by assuming a complete compensation of the arm-wheel weight momentum around the pivot, $M_{W}$.

$$
M_{W}=m_{b} g L_{b}
$$

Assuming a $10.0 \mathrm{~g}$ mass for the arm-wheel system and a $0.170 \mathrm{~m}$ length for the arm (c.g. at $0.127 \mathrm{~m}$ from the pivot), $M_{W}$ resulted equal to $0.025 \mathrm{Nm}$. A $31.8 \mathrm{~g}$ value for $m_{b}$ then results, Equation (2), having fixed its distance from the pivot, $L_{b}$, at $0.080 \mathrm{~m}$.

\section{Sizing the Locking Subsystem}

A detail of the structural scheme of the locking subsystem is illustrated in Figure 8. The system releases the landing gear arm during the entire motion (deployment-retraction), while it keeps the arm blocked when fully retracted and fully deployed. The release occurs activating the small spring of the locking system, on the right (see Figure $8 b$ ).

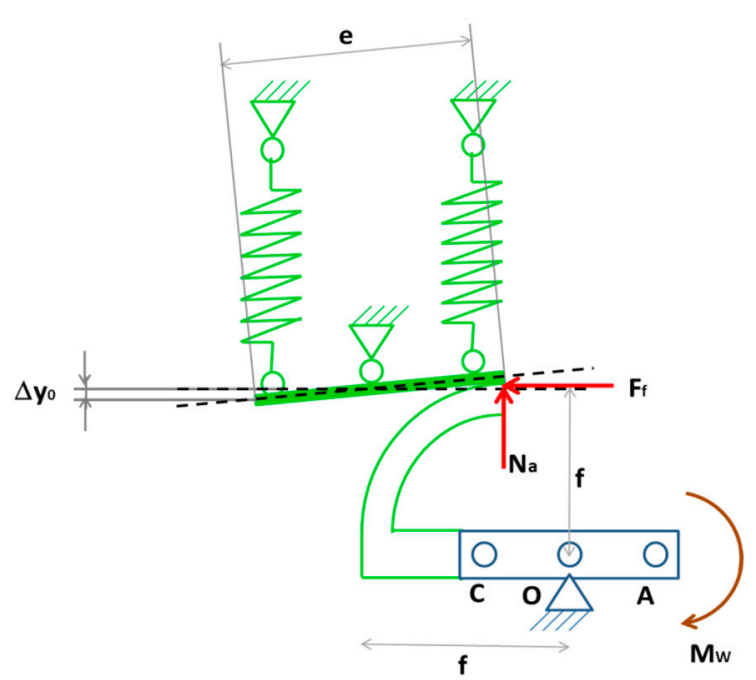

(a)

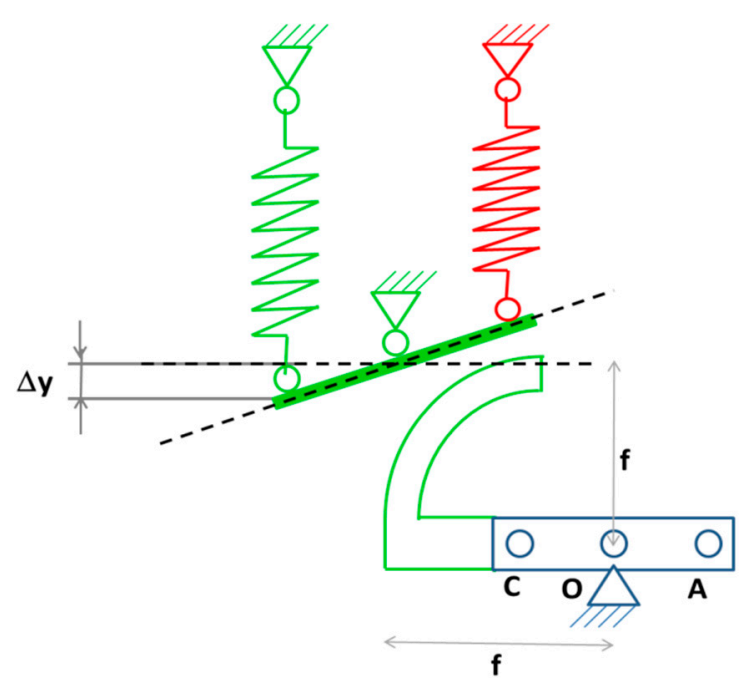

(b)

Figure 8. Locking subsystem structural scheme: locking condition (a); unlocking condition (b). The points $\mathrm{O}, \mathrm{A}$ and $\mathrm{C}$ represent the landing gear arm pivot and the bottom hinges of the SMA springs used to deploy the arm (see Figure 3); $\Delta y_{0}$ and $\Delta y$ indicate the initial and final vertical displacements of the left spring, with respect to the pivot of the friction element (green bold line); the quote $e$ indicates the extension of this element, whose minimum distance with respect to the pivot $\mathrm{O}$ (contact with the circular slide) is equal to $f$; finally, $\mathrm{N}_{\mathrm{a}}, F_{f}$ and $M_{\mathrm{w}}$ indicate the normal contact reaction, the corresponding tangential friction and the moment of the weight of the arm with respect to the pivot $\mathrm{O}$.

Landing gear rotation around $\mathrm{O}$ is avoided through the contact friction force $F_{f}$, between two aluminum elements, namely: a circular slide connected to the gear arm and a friction element (runner), having a length e and connected to two passive springs, Figure 7a. In the blocked condition, the springs undergo a displacement $\Delta y_{0}$, forced by the initial slide layout. The activation of the right spring produces a further displacement $\Delta y$, generating a gap between the two elements and then allowing the arm rotation, Figure $8 \mathrm{~b}$.

The first step to size the system components is to estimate of the friction force able to balance the downward weight moment around the pivot $\mathrm{O}$. This equilibrium can be formalized as:

$$
F_{f} \cdot f=W \cdot \overline{c g}
$$


where the right and left sides express the friction and the arm-wheel weight momentum, respectively. The Equation (3) neglects, conservatively, the concentrated balancing mass, $m_{b}$, effects. If the slide has a $0.050 \mathrm{~m}$ radius, $f$, Equation (3) gives a $0.49 \mathrm{~N}$ balancing friction. Considering a friction coefficient $\mu=1.4$, a $0.36 \mathrm{~N}$ normal action, $\mathrm{N}_{\mathrm{a}}$, resulted. The friction coefficient was assumed as average within the aluminum-aluminum contact component range reported in [21]. It is worth noting that a normal force of $0.36 \mathrm{~N}$ is the minimum value necessary to assure a balancing couple and, thus the locking; it is possible to increase the stretching of the bias spring on the left; this will have the beneficial effect of increasing the friction and thus the lock performance.

For this case, two springs were used of the same material, external diameter and wire diameter of the ones used for the deployment subsystem; the only difference is the no loaded length, $L_{0, \text { lock., }}$ and the number of windings, $5.5 \mathrm{~mm}$ and $7 \mathrm{~mm}$, respectively.

The active springs perceives two actions: the reaction due to the antagonistic spring and the normal action due to the contact. Since these forces have opposite sense, if the stretching of the active spring is low, it risks working in compression; however, the stretching cannot overcome a certain level, for the material shear stress limitation. Considering the above mentioned value of $L_{0, \text { lock. }}$ an imposed stretching $\Delta y_{0}$ of $10 \mathrm{~mm}$ would lead to an acceptable shear stress (206 MPa, computed through Equation (1)) and would generate the situation illustrated in Figure 9.

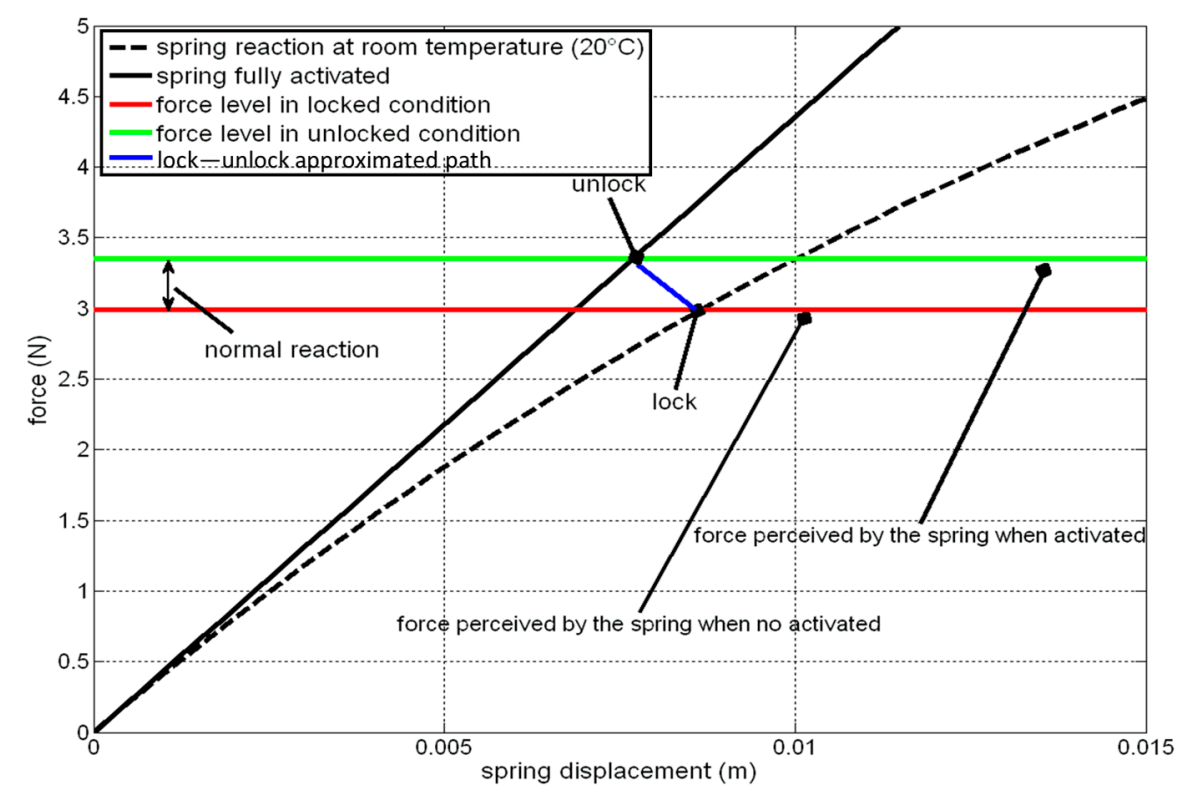

Figure 9. Force-displacement curves for the springs of the locking subsystem: room temperature (black dashed line), full austenite (black solid line), force level including the normal reaction (red line-locked condition), force level without contact (green line-unlocked condition, spring fully activated), lock-unlock approximated path (blue line).

In this figure, both the no activated (room temperature) and fully activated force-displacement curves were reported for the active spring (dashed and solid black lines, respectively). The spring is initially in equilibrium in lock condition. The corresponding point is identified by the intersection between the black dashed line and the red line, representing the force level acting onto the active spring, given by the antagonistic spring reaction minus the normal force, $\mathrm{N}_{\mathrm{a}}$. The activation of the spring causes a sudden decrease of the contact normal force that goes rapidly to zero. The blue line just connects the initial locking point with the final unlocking point, but does not represent the real path of the transformation, being nonlinear because of the nature of the contact force. The force perceived by the active spring (green line) is at the end of the greater transformation. The difference between the green and the red curves is precisely the normal action $(0.36 \mathrm{~N})$. 


\section{Integration within the Unmanned Aerial System}

After defining the static and dynamic behavior of the SMA based subsystems, the integration problem was dealt with [22]. After some preliminary tradeoff between requirements and design, we decided to place the four arms, integrated with the SMA springs within the available space (see the specifications); after hypothesizing a housing compatible with the retracted, deployed, and intermediate configurations, the dimensioning of the supports was addressed. The chosen solution had to guarantee a solid and robust connection with the inner supporting structure of the UAV and assure the gear deployment as from the conceptual design. Some computer-aided design, CAD, schemes are reported below, in order to highlight the integration aspects of the system.

As shown in Figure 10a, "L" sized plate elements, namely "connecting supports" were used as link between the deployment system and the UAV supporting plate. According to the design outcomes, the hinges of the springs and the hubs were placed on the connection supports. The hubs were realized through flanges circularly shaped on one side for sliding onto the runner of the locking subsystem, and finally, the springs of the two subsystems were mounted in antagonistic configuration, in equilibrium in retracted attitude.

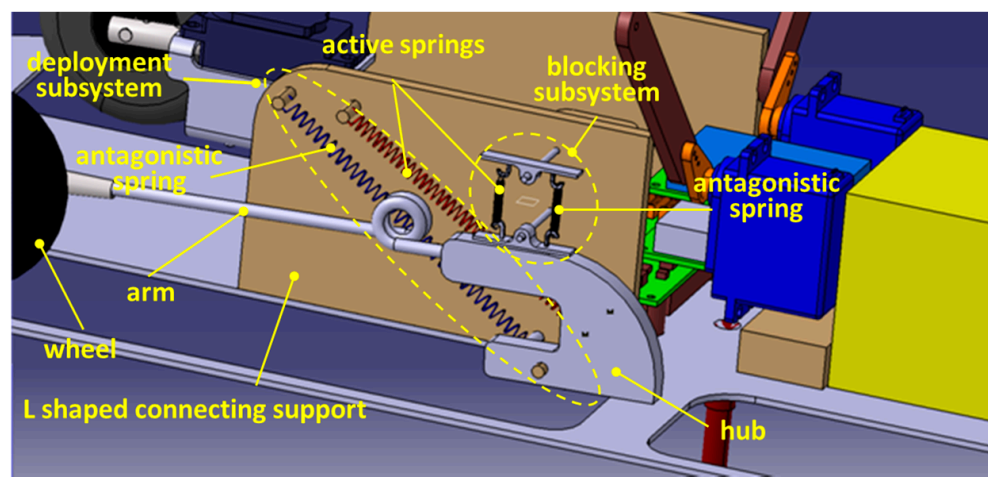

(a)

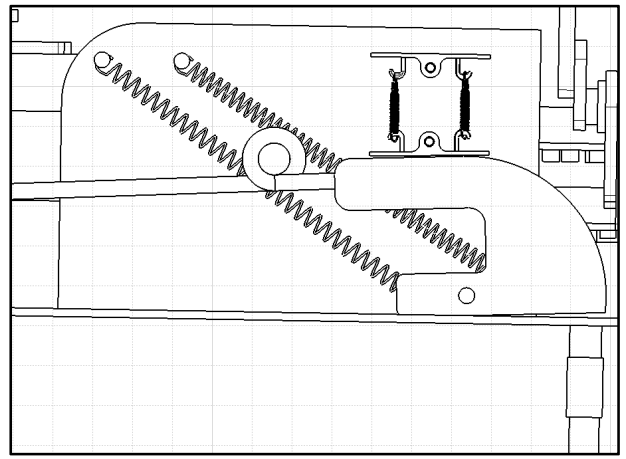

(b)

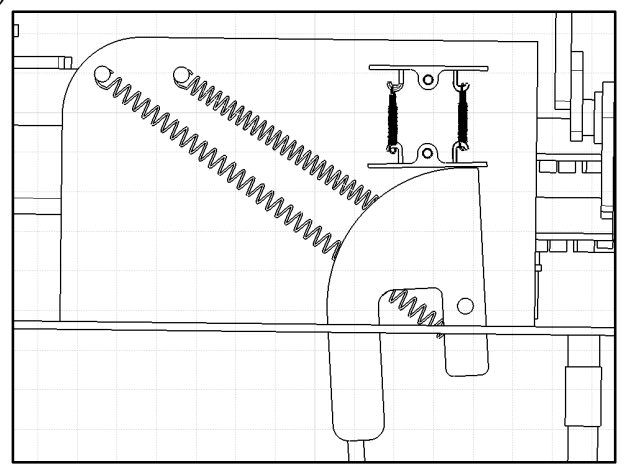

(c)

Figure 10. Computer-aided design details of the deployment and blocking subsystems (a); attitude in retracted (b) and deployed configuration (c).

The main features of the SMA landing gear system are reported in Table 3.

Table 3. Characteristics of deployment and blocking subsystems.

\begin{tabular}{ccccccccc}
\hline $\begin{array}{c}\text { Number } \\
\text { of Arms }\end{array}$ & $\begin{array}{c}\text { Arm Section } \\
\text { Diameter } \\
(\mathbf{m m})\end{array}$ & $\begin{array}{c}\text { Arm } \\
\text { Material }\end{array}$ & $\begin{array}{c}\text { Arm } \\
\text { Length } \\
\mathbf{( m )}\end{array}$ & $\begin{array}{c}\text { Arm } \\
\text { Weight } \\
\mathbf{( g )}\end{array}$ & $\begin{array}{c}\text { Wheel } \\
\text { Diameter } \\
\mathbf{( m )}\end{array}$ & $\begin{array}{c}\text { Wheel } \\
\text { Weight } \\
\mathbf{( g )}\end{array}$ & $\begin{array}{c}\text { Wheel } \\
\text { Material }\end{array}$ & $\begin{array}{c}\text { Hub } \\
\text { Material } \\
\text { Weight } \\
\mathbf{( g )}\end{array}$ \\
\hline 4 & 4.0 & $\begin{array}{c}7075 \mathrm{~T} 6 \\
\text { Aluminum } \\
\text { alloy }\end{array}$ & 0.17 & 10 & 0.65 & 73.0 & $\begin{array}{c}\text { Rubber or } \\
\text { similar }\end{array}$ & $\begin{array}{c}7075 \mathrm{~T} 6 \\
\text { Aluminum } \\
\text { alloy }\end{array}$ \\
\hline
\end{tabular}




\section{Functionality Tests}

In order to verify design approach and assumptions, we realized a conceptual "test specimen" able to reproduce the structural scheme of the deployment subsystem. It consisted of a supporting structure on which holes were drilled at the pivot and at the spring anchoring hinges (points $\mathrm{O}, \mathrm{B}$ and $\mathrm{D}$, respectively). Shafts, integrated with bushes reducing the friction, were placed into the holes. Then, the shaft on point $\mathrm{O}$ was integrated with a drilled aluminum component, supporting the hinges A and C. A retainer shaft element was added as shown in Figure 11a, to avoid undesired crossing of the horizontal position during the retraction. Two identic springs featured as specified in Table 2 were mounted. The shafts $C$ and $D$ were connected to power supply terminals to heat the top spring and they were integrated with a thermocouple and an angular sensor (Linear Variable Displacement Transducer, LVDT).

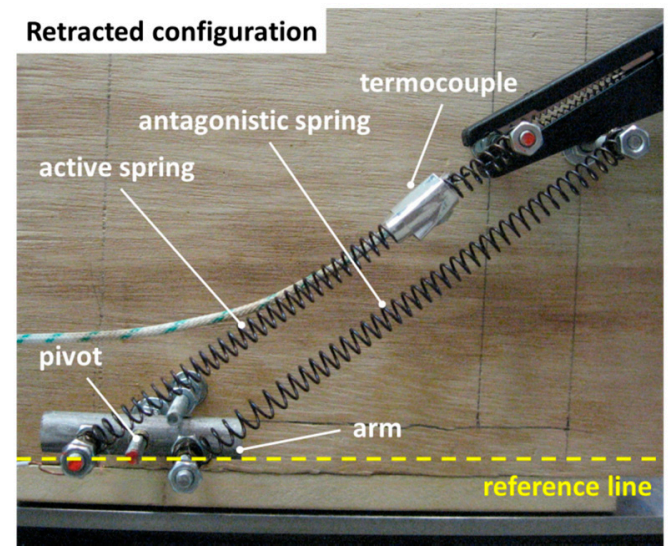

(a)

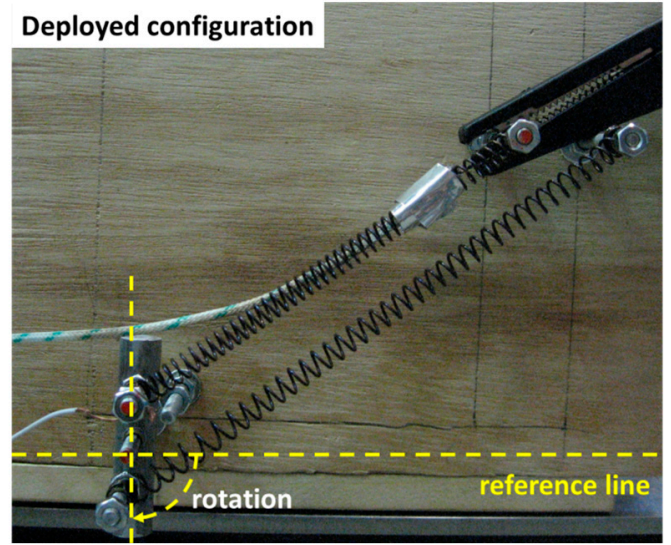

(b)

Figure 11. Test specimen: retracted (a) deployed configuration (b).

A dedicated experimental setup was assembled to execute the tests (see the scheme and a photograph in Figure 12). The instrumentation reported below was used for this scope:

- Acquisition system: IMC Cronos PL/8, Sampling rate $20 \mathrm{kHz}$;

- Oscilloscope: Tektronix-TDS 3014B, Sampling rates to $5 \mathrm{GS} / \mathrm{s}$;

- Power supply: DELTA Elektronika ES 030-10: 0-30 V, 0-10 A;

- Signal generator: Agilent 33220A, 14-bit, $50 \mathrm{MSa}$ /s;

- Temperature sensor: $\mathrm{K}$ thermocouple; measurement range: $-200-1260{ }^{\circ} \mathrm{C}$, sensitivity: $41 \mu \mathrm{V} /{ }^{\circ} \mathrm{C}$;

- Angular sensor: BOURNS-3590S-2-502L-POTENTIOMETER; measurement range: $0^{\circ}-3600^{\circ}$, resolution: $1^{\circ}$.

Thanks to the signal generator instrument and using the function "generator", a step signal was produced to drive the amplifier, this way supplying the prototype with an "on-off" current law. Figure 13 describes a single deployment-retraction cycle. The period of the cycle was set to $150 \mathrm{~s}$, and split into two phases: the activation-deployment phase and the deactivation-retraction phase. The black line describes the logic-driving signal produced by the function generator, assuming a non-zero value in the first $8 \mathrm{~s}$ of the cycle. Within this time, the circuit is supplied with $0.5 \mathrm{~V}-2.3 \mathrm{~A}$ electrical signal. A sudden arise of the temperature was registered (red line). A maximum rotation of $90^{\circ}$ was obtained for a temperature of $110^{\circ} \mathrm{C}$. At this point ends the deployment phase (red zone of the graph). It is important to note that, due to the thermal inertia of the spring material, after the power supplier shutdown the temperature continues to arise for about $1 \mathrm{~s}$ up to $113^{\circ} \mathrm{C}$. After this, the cooling starts (light blue zone of the graph), but the system remains in the fully actuated condition for $29 \mathrm{~s}$ until the inverse transformation starts, highlighted by the slope variation of the temperature line (see Figure 13). 
The transformation starts at $56{ }^{\circ} \mathrm{C}$ and a time range of $113 \mathrm{~s}$ is needed to come back to the retracted condition and to arrive at room temperature. Figure 13 shows that, due to the pre-load level, the temperature transformation value, from austenite to martensite, is reasonably higher than the value (Ms temperature) reported in Figure 4.

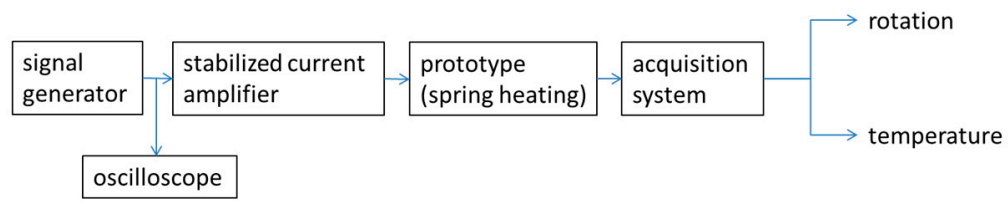

(a)

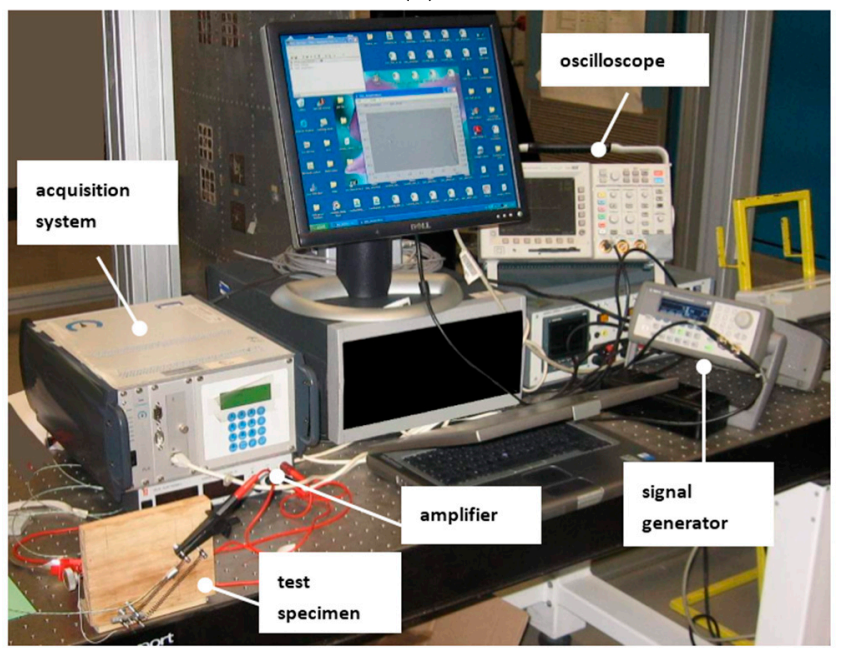

(b)

Figure 12. Setup diagram (a); instrumentation (b) for the experimental characterization of the SMA based deployable arm prototype.

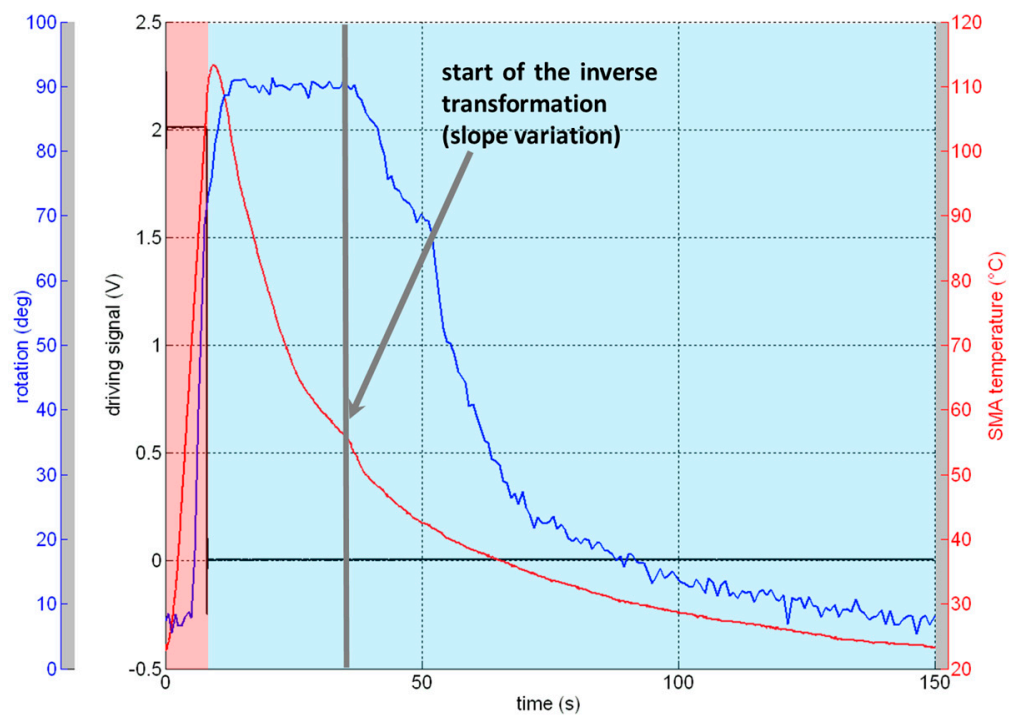

Figure 13. Detail of a single deployment-retraction cycle: activation-heating (red zone), deactivation-cooling (light blue zone). The red, blue and black lines represent the SMA temperature, the induced rotation of the arm and the logical signal used to drive the activation. 
The above mentioned cycle was repeated different times to verify the system performance repeatability. In Figure 14, on the left side, some rotation-temperature cycles are reported, giving evidence of the possibility of covering the required rotation of $90^{\circ}$. On the right side of the figure, rotation $v s$. temperature cycles are reported to give an idea of the overlap of the cycles.

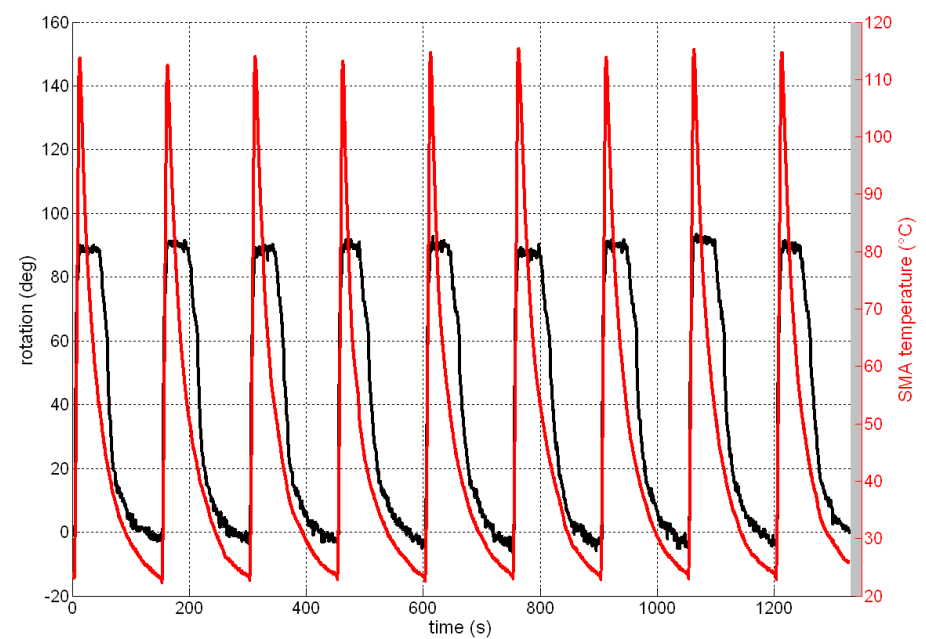

(a)

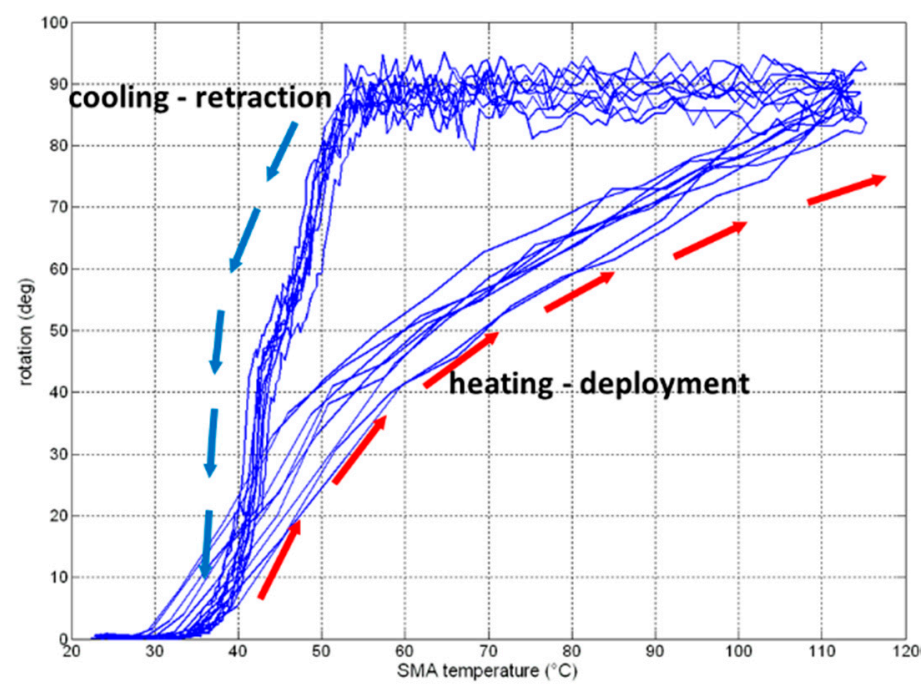

(b)

Figure 14. (a) Device rotation (red line, left axis) and temperature cycles (black line, right axis) vs. time (horizontal axis); (b) the blue curves in the plot on the right describe the evolution of the device rotation (left axis) vs. the temperature (right axis) and are reported for several activation cycles.

\section{Comparison with a Conventional Actuation System}

The design and development of landing gear encompasses several engineering disciplines such as structures, mechanical systems, aerodynamics, material science, and so on. The conventional landing gear design and development for aerospace vehicles is based on the availability of several critical components/systems such as forgings, machined parts, mechanisms, sheet metal parts, electrical systems, and a wide variety of materials such as aluminum alloys, steel, titanium, beryllium, and polymer composites. As the science of materials is progressing continuously, it is natural that the use of new materials will replace older designs with new ones, like ones with smart material spring as actuator. 
Current small unmanned aerial systems and aero models, typically, use servomechanisms linked to retractable landing gear to provide leg activation/retraction.

A servomechanism consists of a large number of moving parts such as gears, bearings, shafts, motor coils, etc. The complexity of a servo requires a considerable percentage of the volume, power, and weight of the entire UAV. Moreover, the reliability of the system strongly depends on the number of components moving each other's. One of the purposes of the design presented in this work was the global simplification of the actuation part, basically constituted by monolithic actuator components (active springs), whose action is modulated through identical springs (working in an antagonistic way).

A comparison was performed between a conventional servo actuator, used for this kind of application [23], and the SMA based one.

When designing for a particular application, several key parameters are specified, including output force, displacement, and frequency. Size and power constraints may also be specified. Based on these few parameters alone, it is desired to be able to look at the vast array of existing actuators and see which candidates match. It is important to realize the entire spread of possibilities and alternatives to meet the requirements of a given application. The weight, the housing volume, and the required power were taken into account and compared in Figure 15 and in Table 4.

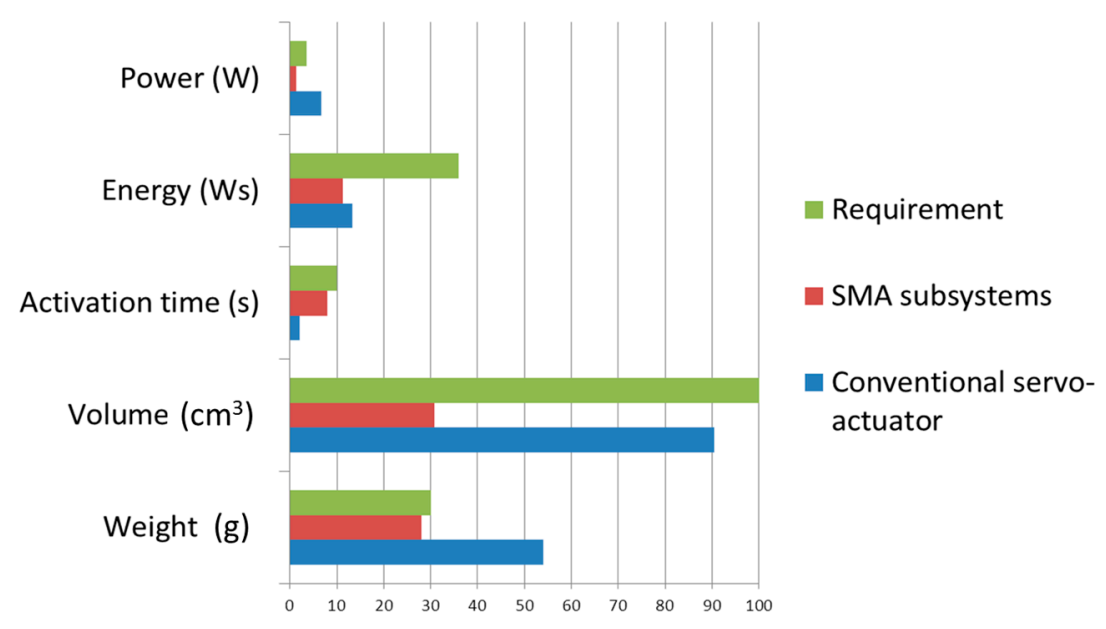

Figure 15. Conventional SMA deployable system comparison vs. requirements.

Table 4. Performance comparison.

\begin{tabular}{ccccc}
\hline Parameter & $\begin{array}{c}\text { Conventional } \\
\text { Servo-Actuator }\end{array}$ & $\begin{array}{c}\text { SMA } \\
\text { Subsystems }\end{array}$ & Requirement & $\begin{array}{c}\text { Deviation Conventional } \\
\text { vs. SMA (\%) }\end{array}$ \\
\hline Weight $(\mathrm{g})$ & 54 & 28 & $\leqslant 30$ & -48.1 \\
Volume $\left(\mathrm{cm}^{3}\right)$ & 90.5 & 30.8 & $\leqslant 100.0$ & -66.0 \\
Activation time $(\mathrm{s})$ & 2 & 8 & $\leqslant 10$ & 300.0 \\
Energy (Ws) & 13.3 & 11.2 & $\leqslant 36$ & -16.2 \\
Power (W) & 6.66 & 1.33 & $\leqslant 3.6$ & -80.0 \\
\hline
\end{tabular}

Let us note that comparisons, based directly on design parameters, will be more useful in the design process. In performing the comparisons, one of the key objectives is to include size (either mass or volume), so the effects of scaling can be observed. It is well known that scaling can have a large effect on some actuation schemes. For the designer who works in several domains (e.g., micro and macro devices) this information is important.

\section{Conclusions and Further Steps}

In the paper at hand, the design of landing gear, based on the shape memory alloy technology, was presented. The system, conceived for a small unmanned aerial vehicle, is made of two subsystems, 
namely, the deployment and locking subsystem. The former one assures the deployment and the retraction of the arms, the latter one assures the maintenance of the fully deployed and retracted attitudes by locking the arm through a friction action.

Both the subsystems are actuated through SMA springs, whose retraction is assured by other identical springs, working in antagonistic way. In the deployment mechanism the springs are mounted around the arm pivot; the heating of one of them leads to an equilibrium shift, with a consequent induced rotation. The locking mechanism is constituted by a runner hinged around a pivot around which two other springs act. When the active spring is cool, the runner is in contact with the arm slider this way avoiding any rotation; when the spring is heated, the runner rotates and releases from the slider enabling its rotation.

After a critical overview of the requirements, issued in terms of deployment angle, activation/deactivation time, system installation, weight, and dynamic behavior, the system's working principle was introduced, describing the main design parameters and their effect on the performance. Then two reference structural schemes were introduced, referring to the equilibrium conditions in the retracted and the deployed configurations.

The evolution of the system from the retracted towards the fully deployed attitude was described. For each rotation value within the operative range $\left(0^{\circ}-90^{\circ}\right)$ the corresponding length of the springs was found out on the basis of geometric assumptions. Then, using the experimental force-displacement curve of the springs, the reaction force of the antagonistic spring was obtained; finally imposing the momentum equilibrium around the arm pivot, the balancing force to be provided by the active spring was found out. In this way, the relation between the displacement of the active spring and the balancing force was obtained. By crossing this curve respectively with the spring not-activated and fully activated curves, the retracted and fully deployed attitudes were identified in terms of displacement and forces required by the active spring.

Based on the information given by the modeling task, a conceptual test specimen was realized. The arm pivot and the hinges of the two springs were placed onto a supporting plate. The pivot was integrated with a beam-like element representing the spring connection hub. After that, the springs were mounted with the prescribed extension so that the hub remained in horizontal position.

The top spring was then supplied by an electrical signal coming from an amplifier, driven by a function generator, in this way different heating-cooling cycle were performed, relating the rotation of the hub to the temperature of the spring and to the supplied electrical signal. The ability of the system to perform the full deployment was tested, as well as the repeatability of the performance.

Finally, a comparison of the main performance of the system was performed assuming as reference a traditional servo-actuator used for this kind of application.

The work presented highlighted the possibility to realize a deployable landing gear based on SMA technology and oriented to UAVs. The selected NiTiNol material proved to activate and deactivate at room temperature $\left(20^{\circ} \mathrm{C}\right)$ for the applied pre-load (see working cycle of Figure 13). The extension of the use to a different and wider range of temperatures (typical for an aeronautical product of this class) can be obtained by selecting a specific alloy, having activation temperatures under the prescribed loads higher than the maximum operational temperature.

This choice is possible within the wide range of alloys offering activation temperatures in the wide range of -200 to $+100{ }^{\circ} \mathrm{C}$. In the present work, however, attention was paid to the mechanical feasibility of the concept, leaving to future studies the application to specific cases and the release of executive designs.

Further steps will be carried out and further efforts will be spent on this topic. The conceptual design above illustrated will be further developed and optimized up to arrive at an executive drawing of the system. The resulting device will be installed on board the UAV. Tests, both static and dynamic, will be addressed with the scope of characterizing the behavior of the landing gear integrated within the UAV and to highlight and solve eventual problems due to the interaction with the other onboard 
systems. Then the flight tests will be performed, monitoring with dedicated sensors the behavior of the landing gear components during a typical mission.

Acknowledgments: This work was developed by the Italian Defence Ministry, in the framework of the Military National Research Program (PNRM) and under the contract CIRA-POI-11-0495, related to activities performed within the Small Unmanned Aerial System design and development. Moreover, the authors would like to recall that the DSC diagram of Figure $4 \mathrm{~b}$ has been provided by Dr. Giovanni Cosentino, Innovative Materials Division of CIRA.

Author Contributions: Salvatore Ameduri dimensioned the SMA based deployment and blocking systems and organized the experimental functionality campaign; Antonio Concilio provided hints on SMA applications as derived from the related studies and the design approach; Moving from the UAS needs, Nunzia Favaloro produced the point specifications for the deploying system and provided benchmark info (conventional actuation system); Lorenzo Pellone managed the integrated Digital Mock-Up giving specific suggestions for the system layout.

Conflicts of Interest: The authors declare no conflict of interest.

\section{Abbreviations}

A

$\mathrm{A}_{\mathrm{f}}$

$\mathrm{A}_{\mathrm{S}}$

b

B

$b_{\mathrm{W}}$

C

c.g.

d

D

$\mathrm{D}_{\mathrm{s}}$

$d_{\mathrm{w}}$

$e$

$\mathrm{F}$

$F_{f}$

$f$

g

$\mathrm{h}$

$K_{\vartheta}$

$K_{\mathrm{n}}$

L

$L_{0, \text { depl. }}$

$L_{0, \text { lock. }}$

$L_{\mathrm{b}}$

LVDT

$m_{\mathrm{b}}$

$\mathrm{M}_{\mathrm{f}}$

$\mathrm{M}_{\mathrm{S}}$

$M_{\text {W }}$

$\mathrm{N}_{\mathrm{a}}$

$\mathrm{O}$

PNRM

$S$ antag.

SSMA act.

SUAS

UAS

UAV connection point between the antagonistic spring and the arm

austenite finish temperature: temperature at which, without applied loads, the transformation of martensite into austenite ends

austenite start temperature: temperature at which, without applied loads, the transformation of martensite into austenite starts

abscissa of point $\mathrm{D}$ with respect the point $\mathrm{O}$

hinge connection between the antagonistic spring and the supporting structure

distance between the center of gravity and the pivot $\mathrm{O}$

connection point between the active spring and the arm

center of gravity

distance between the $\mathrm{A}$ and $\mathrm{C}$ and $\mathrm{B}$ and $\mathrm{D}$ points

hinge connection between the active spring and the supporting structure

mean diameter of the spring

diameter of the spring wire

length of the friction element

force acting on the spring

friction force

distance of the friction force $\mathrm{F}_{\mathrm{f}}$ from the pivot or external radius of the component (1)

acceleration of gravity: $9.81 \mathrm{~m} / \mathrm{s}^{2}$

ordinate of the points $\mathrm{B}$ and $\mathrm{D}$ with respect the point $\mathrm{O}$

equivalent torque rigidity around the point $\mathrm{O}$

rigidity of the no activated springs projected normally to the arm

distance between the pivot $\mathrm{O}$ and the wheel axis

length of the springs of the deployment subsystem without loads

length of the springs of the locking subsystem without loads

distance of the balancing concentrated mass from the pivot

Linear Variable Differential Transformer

balancing mass

martensite finish temperature: temperature at which, without applied loads, the transformation of austenite into martensite ends

martensite start temperature: temperature at which, without applied loads, the

transformation of austenite into martensite starts

momentum of the arm-wheel components around the point $\mathrm{O}$

normal action

hinge of the landing gear arm

Military National Research Program

displacement of the antagonistic spring

displacement of the active spring

Small Unmanned Aerial System

Unmanned Aerial Systems

Unmanned Aerial Vehicle 


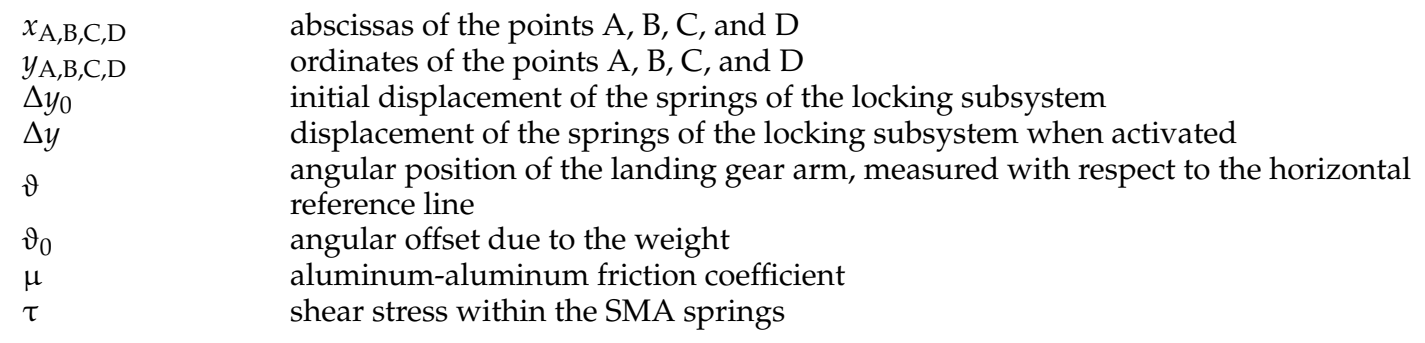

\section{References}

1. Nagy, A.; Rohacs, J. Unmanned Measurement Platform for Paragliders. In Proceedings of the 28th International Congress of the Aeronautical Sciences, Brisbane, Australia, 23-28 September 2012; pp. 1-10.

2. Eschmann, C.; Kuo, C.-M.; Kuo, C.-H.; Boller, C. Unmanned Aircraft Systems for Remote Building Inspection and Monitoring. In Proceedings of the 6th European Workshop on Structural Health Monitoring, Dresden, Germany, 3-6 July 2012; pp. 1-8.

3. Jacob, J.; Smith, S.; Cadogan, D.; Scarborough, S. Expanding the Small UAV Design Space with Inflatable Wings; Society of Autmotive Engineers, Inc.: Los Angeles, CA, USA, 2007; pp. 1-8.

4. Carpenter, B.; Lyons, J. Lightweight Flexible Solar Array Experiment Summary; NASA Report. Goddard Space Flight Center: Greenbelt, MD, USA, 8 August 2001. Available online: http:/ /www.eoc.csiro.au/hswww / oz_pi/techforum/Validation_Reports/LFSA.pdf.

5. Petry, G.; Behr, R. The Parafoil Technology Demonstration Project (PTD) lesson learned and Future Visions. In Proceedings of the 15th CEAS/AIAA Aerodynamic Decelerator Systems Technology Conference AIAA 99-1755, Toulouse, France, 8-15 June 1999; pp. 1-8.

6. Jacobs, S.; Coconnier, C.; di Maio, D.; Scarpa, F.; Toso, M.; Martinez, J. Deployable auxetic shape memory alloy cellular antenna demonstrator: Design, manufacturing and modal testing. Smart Mater. Struct. 2012, 21, 1-12. [CrossRef]

7. Calkins, F.T.; Mabe, J.H. Shape Memory Alloy Based Morphing Aerostructures. J. Mech. Des. 2010, 132, 111012. [CrossRef]

8. Pollard, E.L.; Jenkins, C.H.M. Shape Memory Alloy Deployment of Membrane Mirrors for Spaceborne Telescopes. J. Spacecr. Rocket. 2007, 44, 109-120. [CrossRef]

9. Sofla, A.Y.N.; Elzey, D.M.; Wadley, H.N.G. Shape morphing hinged truss structures. Smart Mater. Struct. 2009, 18, 1-8. [CrossRef]

10. Unsworth, J.D.; Waram, T.C. Shape Memory Alloy Tubular Deployment System. U.S. Patents 5,846,247, 8 December 1998.

11. Dayananda, G.N.; Varughese, B.; Subba Rao, M. Shape Memory Alloy Based Smart Landing Gear for an Airship. J. Aircr. 2007, 44, 1469-1477. [CrossRef]

12. Caswell, G.; Dodd, E. Unmanned Aerial Vehicles Reliability Study, 2003. Available online: http:// www.dfrsolutions.com/white-papers/improving-unmanned-aerial-vehicle-uav-reliability/ (accessed on 31 January 2016).

13. Abdullah, E.J.; Bil, C.; Watkinsm, S. Testing of Adaptive Airfoil for UAV Using Shape Memory Alloy Actuators. In Proceedings of the 27th International Congress of the Aeronautical Sciences, Nice, France, 19-24 September 2010; pp. 1-9.

14. Ameduri, S.; Brindisi, A.; Tiseo, B.; Concilio, A.; Pecora, R. Optimization and Integration of Shape Memory Alloy (SMA)-Based Elastic Actuators within a Morphing. J. Intell. Mater. Syst. Struct. 2011, 23, 381-396. [CrossRef]

15. Ameduri, S.; Concilio, A.; Favaloro, N.; Pellone, L. A SMA based Landing Gear conceived for Unmanned Aerial Vehicles. In Proceedings of the International Conference on Shape Memory and Superelastic Technologies Conference, Prague, Czech Republic, 20-24 May 2013.

16. Tanaka, K.; Kobayashi, S.; Sato, Y. Thermo-Mechanics of Transformation Pseudo-elasticity and Shape Memory Effect in Alloys. Int. J. Plast. 1986, 2, 59-72. [CrossRef]

17. Liang, C.; Rogers, C.A. One-Dimensional Thermomechanical Constitutive Relations for Shape Memory Material. J. Intell. Mater. Syst. Struct. 1990, 1, 207-234. [CrossRef] 
18. Brinson, L.C. One-Dimensional Constitutive Behavior of Shape Memory Alloys: Thermomechanical Derivation with Non-Constant Material Functions and Redefined Martensite Internal Variable. J. Intell. Mater. Syst. Struct. 1993, 4, 229-242. [CrossRef]

19. Boyd, J.; Lagoudas, D. A Thermodynamical Constitutive Model for Shape-Memory Materials. Part I. The Monolithic Shape-Memory Alloy. Int. J. Plast. 1996, 12, 805-842. [CrossRef]

20. Progetto di un Attuatore in SMA. Available online: http://www.ing.unitn.it/ \{\}colombo/APPLICAZIONE_ DELLE_LEGHE_A_MEMORIA_DI_FORMA/4Progetto\%20di\%20un\%20attuatore\%20con\%20una\% 20SMA.html (accessed on 31 January 2016).

21. Coefficienti di Attrito. Available online: http://www.tecnocentro.it/ita/tabella_coeff_attrito.htm (accessed on 31 January 2016).

22. Currey, N.S. Aircraft Landing Gear Design: Principle and Practices; AIAA Education Series; American Institute of Aeronautics and Astronautics: Washington, DC, USA, 1988; pp. 33-37.

23. Carrelli Retrattili Elettrici Economici. Available online: http://www.rcaeromodellismo.it/main/2012/ carrelli-retrattili-elettrici-economici/ (accessed on 31 January 2016).

(C) 2016 by the authors; licensee MDPI, Basel, Switzerland. This article is an open access article distributed under the terms and conditions of the Creative Commons Attribution (CC-BY) license (http://creativecommons.org/licenses/by/4.0/). 